\title{
Birth preparedness and complication readiness among pregnant women in Ethiopia: a systematic review and Meta- analysis
}

Abadi Kidanemariam Berhe ${ }^{1 *}$, Achenef Asmamaw Muche ${ }^{2}$, Gedefaw Abeje Fekadu ${ }^{3}$ and Getachew Mullu Kassa ${ }^{4}$

\begin{abstract}
Birth preparedness and complication readiness is an essential component of safe motherhood programs that promote appropriate utilization of skilled maternal and neonatal care. Preparing for childbirth and its probable complications can reduce delays in seeking care. In Ethiopia, there were limited data on birth preparedness and complication readiness at the national level except a small scale studies conducted.This systemic review and metaanalysis study was conducted to assess the national estimates regarding the status of birth preparedness and complication readiness among pregnant women in Ethiopia.

Methods: Preferred Reporting Items for Systematic Reviews and Meta-Analyses (PRISMA) guideline was followed during systemic review and meta-anaysis. The databases used to identify studies were; MEDLINE, PubMed, Google scholar, CINAHL, EMBASE and African Journals Online. Appropriate search terms were used to retrieve published studies conducted in Ethiopia. Joanna Briggs Institute Meta-Analysis of Statistics Assessment and Review Instrument (JBI-MAStARI) was used for critical appraisal of studies. The meta-analysis was conducted using STATA 14 software. Forest plots were used to present the findings of this meta-analysis. The $P^{2}$ test statistics and Egger's test were used to test heterogeneity and publication bias respectively. The pooled prevalence with $95 \%$ confidence intervals (Cl) was computed. Duval and Tweedie nonparametric trim and fill analysis using the random-effect analysis was conducted to account for publication bias and high heterogeneity.
\end{abstract}

Result: Thirteen studies and six thousand four hundred ninety three participants were included in this metaanalysis and overall pooled result showed $32 \%$ with $95 \%(25.6,38.5)$ of the pregnant women were prepared for birth and its complications. In addition, 51.35\% of women save money for birth and emergency case, 38.74\% women identified skilled birth attendant, and only $26.33 \%$ of pregnant women were aware of danger signs during pregnancy. One fifth (20.59\%) of women arranged transportation and $54.85 \%$ of women identified the place of birth. Only 8.18\%pregnant women identified potential blood donor for emergency cases.

Conclusion: Low proportions of pregnant women were prepared for childbirth and its complications. The Ministry of health, Regional health bureaus, health facilities and other stakeholders should work to improve birth preparedness and complication readiness among pregnant women in Ethiopia.

Keywords: Birth preparedness, Complication readiness, Ethiopia, Systemic review and Meta-analysis

\footnotetext{
* Correspondence: abadik021@gmail.com

${ }^{1}$ College of Medicine and Health Sciences, Adigrat University, Tigray, Ethiopia

Full list of author information is available at the end of the article
}

(c) The Author(s). 2018 Open Access This article is distributed under the terms of the Creative Commons Attribution 4.0 International License (http://creativecommons.org/licenses/by/4.0/), which permits unrestricted use, distribution, and reproduction in any medium, provided you give appropriate credit to the original author(s) and the source, provide a link to the Creative Commons license, and indicate if changes were made. The Creative Commons Public Domain Dedication waiver (http://creativecommons.org/publicdomain/zero/1.0/) applies to the data made available in this article, unless otherwise stated. 


\section{Plain English summary}

Delay in responding to the onset of labor and of its complications has a major barrier on reduction of maternal mortality and morbidity. Ethiopia is one of the countries with high maternal mortality, the country introduced different strategies to reduce maternal mortality like free maternal service, employed trained health extension worker at community level, strengthening midwifery professional training. Birth preparedness and complication readiness is nationally endorsed as an essential component of safe motherhood programs to reduce maternal and newborn mortality.

There were different studies conducted in different regions on birth preparedness and complication readiness but there is limited data on the pooled estimates at the national level. There fore the aim of this systematic review and meta analysis was to assess birth preparedness and complication readiness at nationally level in Ethiopia. Thriteen studies were included in this metaanalysis. Only one third of pregnant women were prepared for birth and ready for complication in ethiopia. Specifically this study showed $51.35 \%$ of women saving money, $38.74 \%$ women identified skilled birth attendant and $26.33 \%$ of pregnant women were aware of danger signs during pregnancy. One fifth of women arranged transportation and $54.85 \%$ of women identify the place of birth. Only $8.18 \%$ pregnant women identified potential blood donor for the case of emergency. Ministry of health, Regional health bureaus, health facilities and other stakeholders should work to improve this low birth preparedness and complication readiness among pregnant women in Ethiopia.

\section{Background}

Globally, eight hundred women die every day due to pregnancy or child birth related complications. Almost all maternal deaths (99\%) occur in developing countries, and more than half of this deaths occur in Sub-Saharan Africa [1]. Many of the complications that result in maternal mortality and perinatal deaths like abortion complications, ruptured uterus, puerperal sepsis, postpartum hemorrhage, and preeclampsia/eclampsia are unpredictable, and their onset can be both sudden and severe [2]. Delay in responding to the onset of labor and onset of complications by individual pregnant women, family and health care provider has been shown as major barrier to reducing maternal mortality and morbidity [3].

In many societies, cultural beliefs and lack of awareness inhibit preparation for delivery and seeking care. Due to this reason complications occur in unprepared family could take lots of time in understanding the problem; to get organize, in getting money, in finding transport and reaching the appropriate referral facility. Therefore, this delay in the decision, in reaching health facility and delay in receiving care can be solved by proper use of birth preparedness and complication readiness plan [4-6].

Ethiopia is one of the countries with high maternal mortality ratio (MMR), although the country is striving hard to reducing maternal mortality $[7,8]$. In the last fifteen years; maternal mortality decreased from 871 to 412 per 100,000 live births due to the substantial effort made in improving maternal health services for pregnant and laboring women $[9,10]$. Ethiopia did not achieve the Millennium Development Goal (MDG) which aimed to reduce the MMR to 267 maternal deaths per100,000 live births $[11,12]$. Birth preparedness and complication readiness (BPCR) helps pregnant women how to identify skilled birth attendant, how to identify signs of labor and in recognizing danger signs for pregnancy-related complications. It also helps toreduce other barriers to seeking care, such as transport costs, perceptions of poor quality of care and cultural differences [13].

BPCR components are included in the new World Health Organization (WHO) model for antenatal care as part of antenatal care education in clinic setting [14]. Birth Preparedness and Complication Readiness is one of the strategy to promote timely utilization of skilled maternal and neonatal care timely. Preparing for childbirth and associated complications reduces the three delays of maternal death; delay in recognizine danger signs and decision of seeking care in home, delay in reaching health facility and delay in receiving health care by encouraging pregnant women, their families, and communities to effectively plan for births and prepare for emergencies if they occur $[15,16]$.

Even though BPCR is nationally endorsed as an essential component of safe motherhood programs in West Showa Zone (WSZ), Ethiopia in 1998 [17] low proportion of women are delivering at health facility (26\%) [9] and high proportion of women are suffering from complications related to pregnancy and child birth (28.5\%) [18-20]. Additionally there is limited data about BPCR plan of pregnant women's at the national level, Therefore the aim of this systemic review and meta analysis is to assess mangitude of birth preparedness and complication readiness in Ethiopia and this will helps for policy makers and program coordinators, health professional and other stakeholders who are working on maternal health to have up-to-date information on the status of BPCR at national level.

\section{Methods}

\section{Study design and search strategy}

A systemic review and meta-analysis on birth preparedness and complication readiness in Ethiopia was done using published research articles. Major data bases like; MEDLINE, PubMed, Google scholar, CINAHL, EMBASE 
and African Journals Online were used to review published studies. All published articles up to August/2017 were included in the review. The reference lists of already identified studies were also searched to retrieve additional articles. The search was done using the following search terms; "Birth preparedness", "complication readiness"; "pregnant women", "pregnant women identified skilled birth attendant", "pregnant women saving money for emergency cases", "pregnant women identifying potential blood donor", "pregnant women arrangement for transportation", "pregnant women identifying the place of delivery", Ethiopia separately and/or in combination using the Boolean operators like "OR" or "AND".

\section{Study selection and eligibility criteria}

Inclusion criteria:

* Participants: this review included studies conducted on birth preparedness and complication readiness among pregnant women in Ethiopia.

* Setting: Studies conducted both at community or institution level.

* Article which includes Birth preparedness and complication readiness as outcome

* Time frame: all studies irrespective of time of data collection or publication year

* Publication types: journal articles

* Studies published only in the English language were included in the review

Exclusion criteria:

* Studies which did not reported the outcome variable of this review.

* Repetitive publication

* Studies which did not specify study population and qualitative studies were excluded from systematic review and Meta-analysis

\section{Data extraction and data collection}

Authors jointly prepare and the determined data extraction tool for this study. The tool includes questions on; the name of the author, publication year, study design, data collection period, sample size, study area, participants, response rate and prevalence of birth preparedness and complication readiness. Additionally,the tool contains information on; percentage of women who saved money for birth and emergency case, women who prepared blood donor, women who identified skilled birth attendant, women who were aware of danger signs during pregnancy, women who arranged transportation, women who identified place of birth and women who planed health facility delivery.All authors involved in the data extraction.

Definitions of birth prepardness and complication readiness Birth preparedness and complication readiness is measured by key elements. The key elements includes; arrangement for transportation, saving money for delivery, identify skilled birth attendant, identifying place of delivery and identifying blood donor for the case of emergency $[3,15,21]$. All studies that used the above definition of birth preparedness and complication readiness were included in this review.

\section{Quality assessment}

Articles were reviewed using titles, abstracts and full review. Studies that did not meet inclusion criteria were excluded. Full texts of included studies were examined using the Joanna Briggs Institute Meta-Analysis of Statistics Assessment and Review Instrument (JBI-MAStARI) for critical appraisal.

\section{Publication bias and heterogeneity}

Publication bias and heterogeneity were assessed using the Egger's test and $I^{2}$ statistics, respectively [22]. Statistical significant publication bias was declared at $p$-value less than 0.05 . The heterogeneity of studies was tested using $I^{2}$ test statistics. $I^{2}$ test statistics result of $25 \%, 50 \%$, and $75 \%$ was declared as low, moderate and high heterogeneity respectively [23]. Random effect model was used for meta-analysis test result which indicated statistically significant heterogeneity [24]. For studies which showed the presence of publication bias, the Duval and Tweedie nonparametric trim and fill analysis was conducted to account for publication bias [25].

\section{Statistical methods and analysis}

The analysis was conducted using STATA version 14 . Forest plots were used to present the combined prevalence estimate with the $95 \%$ confidence interval (CI). For studies which didn't present standard error (SE), it was calculated using the formula; $S E=\sqrt{ } \mathrm{p} \times(1-\mathrm{p}) / \mathrm{n}$ in Microsoft excel.The calculated SE and prevalence rate of each study was then entered into STATA software to calculate the overall prevalence and its 95\% CI. The key elements of birth preparedness and complication readiness were presented using separate forest plots.

\section{Results}

\section{Studies included in the meta-analysis}

A total of 819 research articles were identified by electronic search in MEDLINE, PubMed, Google scholar, CINAHL, EMBASE and African Journals Online data bases. Of which, 338were excluded due to duplication, 403through review of titles and 62 through reviewing of abstracts. Additionally 3full-text articles were excluded for not reporting the outcome variable and not including pregnant women as study population. Finally, 13 studies were found to be eligible and included in the Meta-analysis (Fig. 1). 


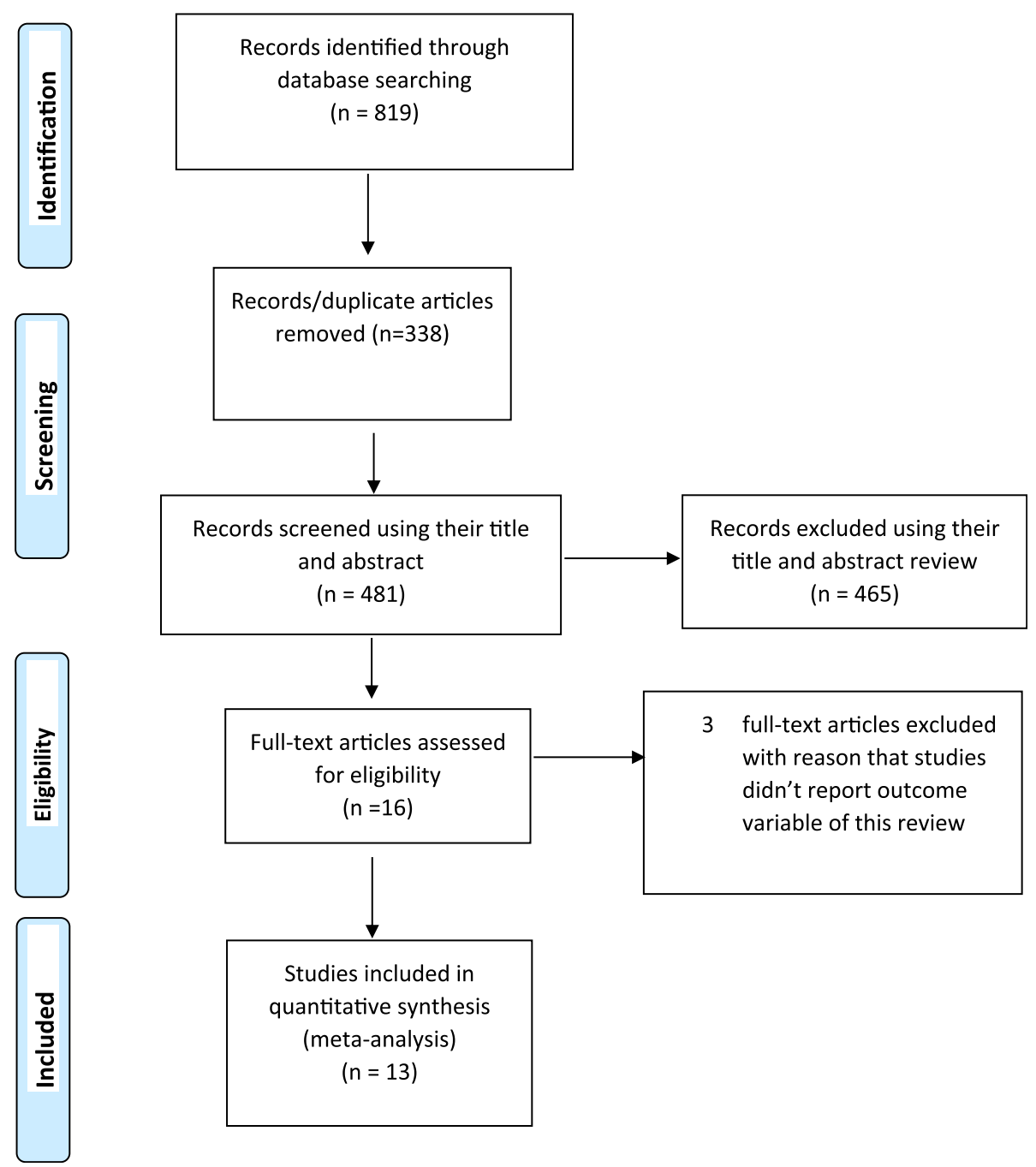

Fig. 1 Flow diagram of the studies included in the Meta-analysis

The sample size of included in this review were totally 6493 which varied among studies included from 220 in Mekelle, Tigray regional state [26] to 819 in SouthWollo, Amhara regional state [27].Four of the included studies were from SNNP [28-31], 2 studies from Tigray Region [26, 32], 2 studies from Amhara Region [27, 33], 2 studies from Oromia Region [34, 35], 1 study from Dire Dawa city administration [36], 1 study from Harari Region [37] and 1 study from Addis Ababa city [38]. Additionally all studies included in the review were crossectional study designs (Table 1).

\section{Birth preparedness and complication readiness among pregnant women in Ethiopia}

The minimum birth preparedness and complication readiness was $16.5 \%$ seen in a study conducted Robe district, Oromia Region [34] whereas the maximum was $56.3 \%$ observed in federal police referral hospital, Addis
Ababa city [38]. The pooled result of the studies showed that only one third (32.04\%; 95\% CI: 25.61, 38.48) of pregnant women were prepared for birth and its complication (Fig. 2).The $I^{2}$ test statistics result showed high heterogeneity $\left(\mathrm{I}^{2=} 97.3 \%, \mathrm{p}=<0.001\right)$ and Eggers test ( $p$-value <0.001). Duval and Tweedie nonparametric trim and fill analysis using the random-effect analysis was conducted to account for publication bias and heterogeneity.

The lowest percentage of women in saving money was $11 \%$ observed in Mekelle, Tigray region [26] and the highest was $89.8 \%$ in Dere Teyara District, Harari [37]. The pooled meta-analysis showed that $51.35 \%$ (95\% CI: $36.40,66.29)$ of pregnant women saved money for childbirth and emergency case (Fig. 3). The $I^{2}$ test result showed high heterogeneity $\left(\mathrm{I}^{2}=99.4 \%, p=<0.001\right)$ but Egger's test showed no statistical significant publication bias $(p$-value $=0.171)$. 
Table 1 Summary characteristics of studies included in study of birth preparedness and complication readiness among pregnant women in Ethiopia

\begin{tabular}{|c|c|c|c|c|c|c|}
\hline S.No & Authors & Study year & Study design & Sample size & Study area & $\mathrm{BPCR}(95 \% \mathrm{Cl})$ \\
\hline 1. & Begashaw et al. & 2017 & Cross-sectional & 392 & Mizan-Tepi University Teaching Hospital, SNNP Region & $41.1[36.23,45.97]$ \\
\hline 2. & & 2016 & Cross-sectional & 405 & Dire Dawa city & $54.7[49.85,59.55]$ \\
\hline 3. & Bitew et al. & 2016 & Cross-sectional & 819 & SouthWollo, Amhara Region & $24.1[21.17,27.03]$ \\
\hline 4. & Berhanu D. Isaac et al. & 2016 & Cross-sectional & 423 & Dere Teyara District, Harari Region & $42.8[38.08,47.52]$ \\
\hline 5. & Dimtsu and Bugssa & 2014 & Cross-sectional & 220 & Mekelle, Tigray Region & $32.3[26.12,38.48]$ \\
\hline 6. & Gebre et al. & 2015 & Cross-sectional & 578 & Wolayta Zone, SNNP Region & $18.3[15.15,21.45]$ \\
\hline 7. & Hailu et al. & 2011 & Cross-sectional & 743 & Sidama Zone, SNNP Region & $17[14.30,19.70]$ \\
\hline 8. & Hiluf and Fantahun & 2008 & Cross-sectional & 534 & Adigrat, Tigray Region & $22[18.48,25.51]$ \\
\hline 9. & Kaso and Addisse & 2014 & Cross-sectional & 575 & Robe district, Oromia Region & $16.5[13.46,19.53]$ \\
\hline 10. & Markos and Bogale & 2014 & Cross-sectional & 580 & Goba district, Oromia Region & $29.9[26.17,33.63]$ \\
\hline 11. & Tiku & 2015 & Cross-sectional & 224 & Addiss Ababa City & $56.3[49.80,62.79]$ \\
\hline 12. & Wuhib Bishaw et al. & 2014 & Cross-sectional & 546 & Basoliben District, Amhara Region & $26.9[23.18,30.62]$ \\
\hline 13. & Zepre and Kaba & 2017 & Cross-sectional & 454 & Abeshige district, SNNP Region & $37.20[32.75,41.65]$ \\
\hline
\end{tabular}

In this sub analysis the heterogeneity test showed the presence of heterogeneity $\left(I^{2}=97.5 \%, p \leq 0.001\right)$ and publication bias (Egger's test $p$-value $<0.001$ ). Therefore, the Duval and Tweedie nonparametric trim and fill analysis using the random-effect analysis was conducted to account for publication bias. Accordingly, the pooled result of studies showed only $8.18 \%$ (95\% CI: $5.30,11.07)$ of women have prepared potential blood donor for emergency case that may occurred during pregnancy and childbirth (Fig. 4).
The lower awarness of danger sign of pregnancy was $2.80 \%$ obseved in a study conducted adigrat, Tigray region [32] where as the maximum awareness was $58.60 \%$ in Dilchora Referral Hospital, Dire Dawa city [36]. Finding of this study showed that only $26.33 \%$ (95\% CI: $15.28,37.38$ ) of pregnant women were aware of danger signs of pregnancy (Fig. 5). The $I^{2}$ test result showed high heterogeneity $\left(\mathrm{I}^{2=} 99.2 \%, \quad p<0.001\right)$ and Eggers test $(p$-value $<0.01)$.

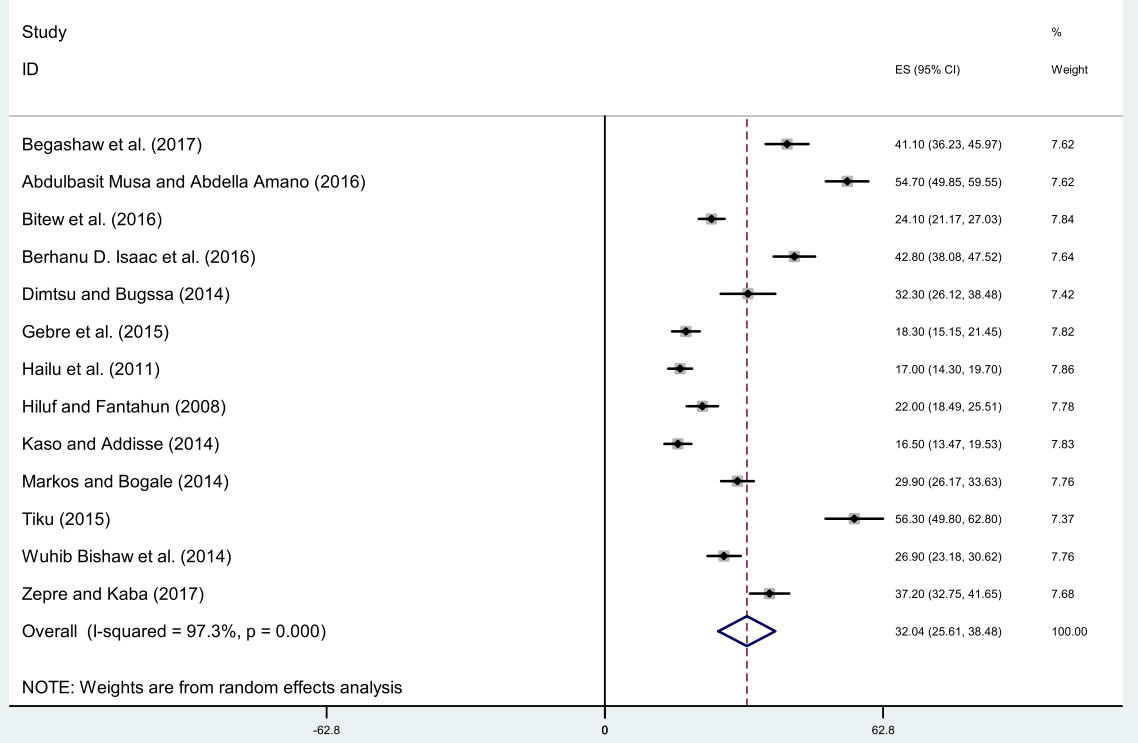

Fig. 2 Forest plot displaying the pooled result of birth preparedness and complication readiness in Ethiopia 


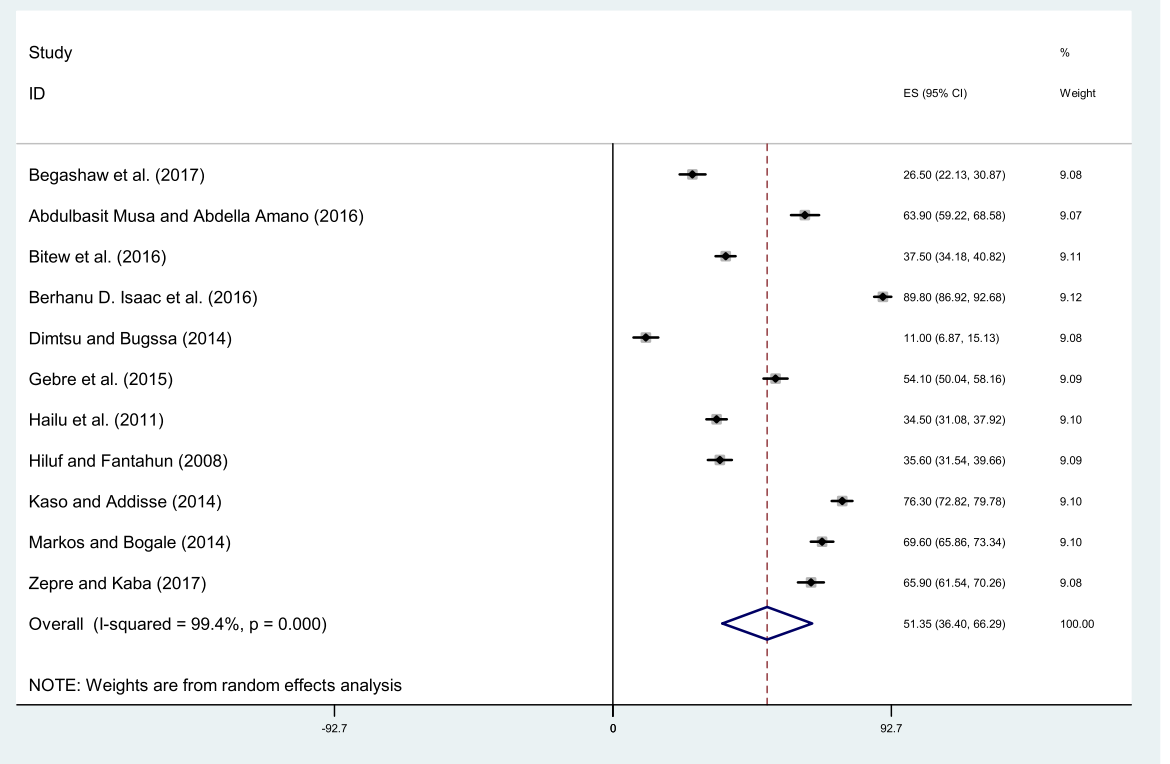

Fig. 3 Forest plot displaying the pooled result of pregnant women save money for birth preparedness and complication readiness in Ethiopia

The lowest percentage of pregnant women who identified skilled birth attendant was 3.0\% which was a study conducted in Robe district, Oromia region [34].Findings of this study showed that only $38.74 \%$ (95\% CI: $22.41,55.07$ ) pregnant women identified skilled birth attendant for delivery (Fig. 6). The $I^{2}$ test result showed high heterogeneity $\left(\mathrm{I}^{2=} 99.7 \%, p<0.001\right)$ and Eggers test $(p$-value $<0.001)$.
There was difference in arrangement of transport as BPCR across regions; the lower magnitude $8.53 \%$ observed in Tigray region and maximum $88.70 \%$ in Dire Dawa city. The overall pooled result of this study showed only that one third (33.93\%) of the pregnant women were arranged transport for birth and emergency case during pregnancy; there was wide variation across

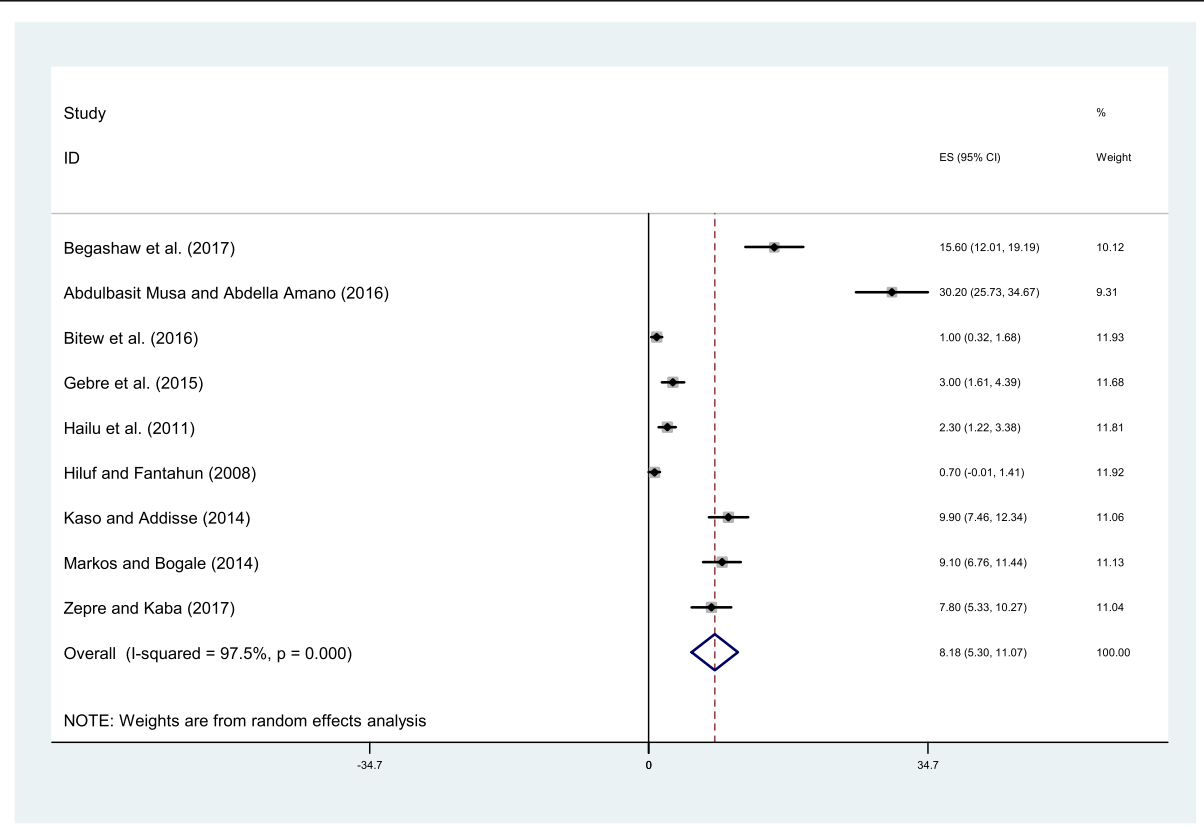

Fig. 4 Forest plot displaying the pooled result of pregnant women prepared blood donor for emergency case during pregnancy and child birth in Ethiopia 


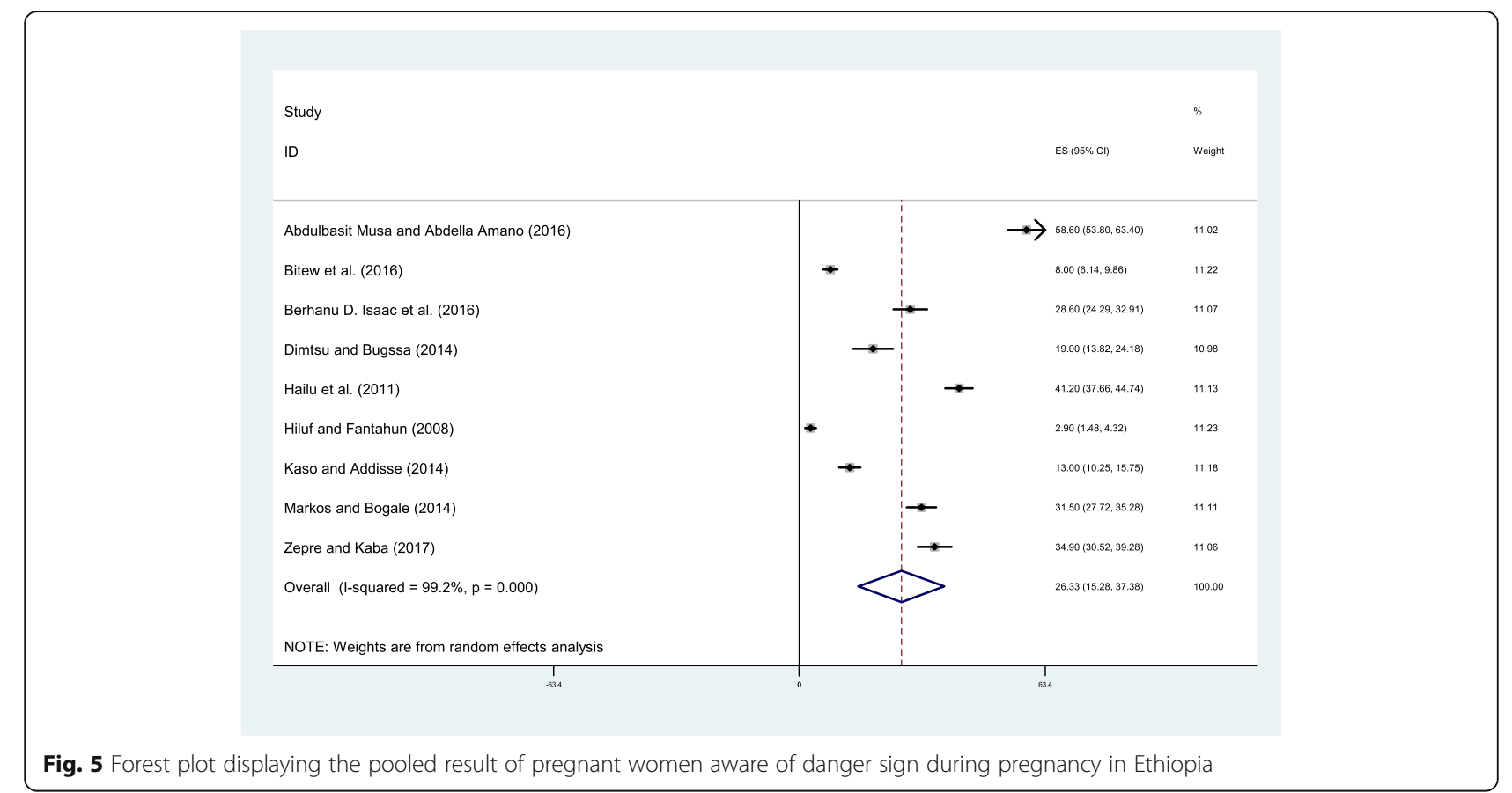

the studies conducted in different regions (Table 2). The $I^{2}$ test result showed high heterogeneity $\left(\mathrm{I}^{2=} 99.7 \%\right.$, $p<0.001)$ and Eggers test $(p$-value $<0.001)$.

The finding of this study showed that $54.85 \%$ of pregnant women had identified the place for delivery (Table 3$)$. The $I^{2}$ test result showed high heterogeneity $\left(\mathrm{I}^{2=} 99.9 \%, p<0.001\right)$ and Eggers test $(p$-value $<0.001)$. Among the pregnant women included in this meta-analysis, only $64.06 \%$ planned to deliver at a health facility.

\section{Discussion}

The aim of this systemic review and meta-analysis was to assess utilization of birth preparedness and complication readiness plan among women's in Ethiopia. Thrteen studies were included in this meta-analysis.

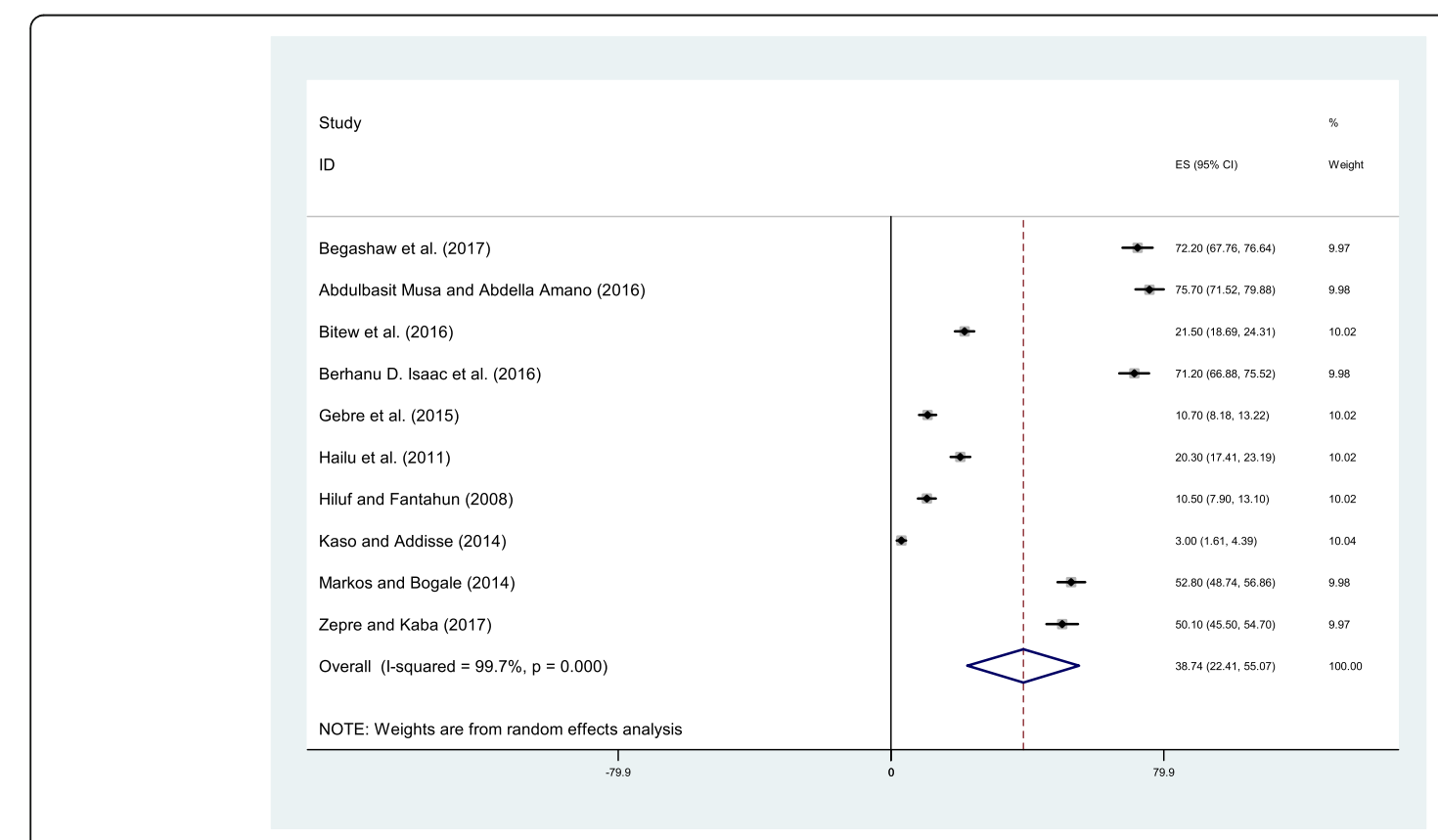

Fig. 6 Forest plot displaying the pooled result of pregnant women identify skilled birth attendant for delivery in Ethiopia 
Table 2 Percent of pregnant women who arranged transport as birth preparedness and complication readiness plan in Ethiopia

\begin{tabular}{lll}
\hline Study area & Number of studies & Estimation $(95 \% \mathrm{Cl})$ \\
\hline SNNP Region & 4 & $33.59(10.56,56.63)$ \\
Dire Dawa city & 1 & $88.70(85.62,91.78)$ \\
Harari Region & 1 & $30.50(26.11,34.89)$ \\
Oromia Region & 2 & $45.64(12.03,79.26)$ \\
Amhara Region & 1 & $10.80(8.67,12.93)$ \\
Tigray Region & 2 & $8.53(2.34,19.39)$ \\
Over all pooled Result & 11 & $33.93(17.71,50.14)$ \\
\hline
\end{tabular}

Finding of this meta-analysis showed that only one-thirds of pregnant women in Ethiopia were prepared for birth and its complication. This finding is relatively similar to the study conducted in Uganda (35\%) [39]. But it was Higher than a study carried out in Gambia (14\%) [40]. In contrast, it is lower than studies carried out in West Bengal, India (57\%) [41], Dehli, India (41\%) [4] and Osun State, Nigeria (61\%) [42].This difference might be due to socio-cultural issues like use of traditional birth attendant, women's educational, economical status and the difference in implementation of prenatal health programs like quality of antenatal care services.

Similarly finding of this review reveals preparation of blood donor, awareness on danger signs and arrangement of transportation for emergency situation were among the poorly utilized elements of birth preparedness and complication readiness plan in Ethiopia.

Failure to recognize signs of complications is one the barriers for the delay in deciding to seek care $[6,43]$. In this study $26.33 \%$ of the pregnant women were aware of danger signsof pregnancy. This result was consistent with a study conducted in Mpwapwa district, Tanzania [44] but it was less than study conducted in District of Ghana [45],West Bengal, India [41], and Abia State, southern Nigeria [46, 47]. In order to improve the awareness of women on danger signs of pregnancy the local and federal government should work intensively on empowering women's education and economic level.

Table 3 Percent of pregnant women who identified place of deliveryas birth preparedness and complication readiness plan in Ethiopia

\begin{tabular}{lll}
\hline Study area & Number of studies & Estimation $(95 \% \mathrm{Cl})$ \\
\hline SNNP Region & 4 & $49.45(0.61,98.29)$ \\
Dire Dawa city & 1 & $98.00(96.64,99.36)$ \\
Harari Region & 1 & $57.20(52.48,61.92)$ \\
Oromia Region & 2 & $61.27(30.60,91.94)$ \\
Amhara Region & 1 & $44.60(41.20,48.00)$ \\
Tigray Region & 2 & $40.86(36.25,45.47)$ \\
Over all pooled Result & 11 & $54.85(32.06,77.64)$ \\
\hline
\end{tabular}

In addition the distance from woman's home to a health facility and lack of transport during emergency are among the barriers for the delay in reaching a health facility. The result of this study showed only one third (33.93\%) of pregnant women had arranged transportation for birth and emergency case; this is relatively consistent to study conducted in Burkina Faso (41.6\%) [48]. But thisfinding was lower compared to studies carried out in Nepal (64.8\%) [49], Kenya (81.9\%) [50], Rural district of Ghana (53.3\%) [45] and West Bengal, India (44.5\%) [41]. This difference could be due to cultural difference like use home delivery, presence of traditional birth attendant as choice for delivery service and lack of awareness can hinder in reaching timely to health facilities. Unavailability of roads in some of the rural setups may be another reason.

Finding of this study also showed that only $54.85 \%$ of pregnant women identified the place of delivery. This result was lower than studies conducted in Punjab, India (90\%) [51] and Osun State, Nigeria (87.5\%) [42]. According to 2016 Ethiopian DHS institutional delivery was very low (26\%) [9].This could be one of the major reasons for the low institutional delivery. In Ethiopia, lack of awareness on the importance of skilled health facility deliveries, cultural beliefs and transport challenges are among causes for high number of deaths during childbirth stated by officials [52]. Therefore health care providers working at community and antenatal care facility should improve awareness through strengthening information, education and counseling at institutional and community level so as to plan women's their place of delivery.

Similarly in this study very few pregnant women $(8.18 \%)$ also prepared potential blood donor for emergency case that may occurre during pregnancy and childbirth. This result was more or less consistent with the study conducted in Osun State, Nigeria(11.3\%) [42] but lower than study carried out in Nairobi, Kenya (28.7\%) [43] and Acra, Ghana (31.6\%) [53]. Those womens which did not prepare potential blood donor are at higher risk of sever morbidity and mortality since bleeding is life threatening situation which needs prompt intervention [54, 55].Therefore womens and support persons should be aware of the need of preparing potential blood donor to prepare for birth and adressing complications.

Overall findings of this study reveals wide gap in ultilization of birth prepardness and complication readiness by women's, this implies the high maternal and neonatal mortality in ethiopia might be related with this poor BPCR plan since poor awareness on danger signs, lack of preparing transport, lack of funds and lack of preparation of blood donor in the event of an emergency predominantly hinders access to emergency obstetric and newborn care (EmONC) in case of complications. Inaddition asystemic review and meta-analysis conducted in 
developing countries on Birth Preparedness and Complication Readiness (BPCR) interventions in reducing maternal and neonatal mortality showed high correlation between BPCR and maternal \& neonatal mortality [56-58].

Therefore clinicians and policy makers should mobilize resources for improving women's BPCR through ongoing training of women's, developing guidelines for provision of appropriate BPCR and regular field supervision.

This meta-analysis didn't address the factors affecting for this low utilization of BPCR, therefore researchers should conduct further studies in this area.

Strenght of this review: Since there was no similar study previously, this review and metaanalysis showed the national pooled image of birth prepardness and complication readiness plan of women's in ethiopia. Strictly following PRISMA guide line and Joanna Briggs Institute Meta-Analysis of Statistics Assessment and Review Instrument (JBI-MAStARI) during critical appraisal was additional strenght of this systemic review and meta analysis.

Presence of high statistical heterogenity in most of the subanalysis were considered as weekness of this review. Inaddition our search was limited to articles published in English language.

\section{Conclusion}

The level of birth preparedness and complication readiness among pregnant women in Ethiopia was found very low as every pregnant woman should be expected to prepare for birth and complication. Specifically, from the key elements of BPCR plan very low percent of pregnant women prepared potential blood donor for the emergency situation during pregnancy and childbirth. Therefore, the Ethiopia ministry of health, Regional health bureaus, health facilities and other stakeholders should work to improve women's birth preparedness and complication readiness plan. We recommended further systematic review and metaanalysis on factors that affect birth preparedness and complication readiness plan of pregnant women in Ethiopia.

\begin{abstract}
Abbreviations
BPCR: Birth Preparedness and Complication Readiness; Cl: Confidence Interval; JBI-MAStARI: Joanna Briggs Institute Meta-Analysis of Statistics Assessment and Review Instrument; MDG: Millennium Development Goals; PRISMA: Preferred Reporting Items for Systematic Reviews and MetaAnalyses; SE: Standard Error; SNNPR: South Nation and Nationalities People Region; WHO: World Health Organization
\end{abstract}

\section{Acknowledgements}

We would like to acknowledge to authors of studies included in this systemic review and meta-analysis.

\section{Availability of data and materials}

All data pertaining to this study is contained and presented in this document.

\section{Authors' contributions}

All authors involved in the design, selection of articles, data extraction, statistical analysis and manuscript writing. All authors read and approved the final draft of the manuscript.
Ethics approval and consent to participate

Not applicable

\section{Consent for publication}

Not applicable

\section{Competing interests}

The authors declare that they have no competing interests.

\section{Publisher's Note}

Springer Nature remains neutral with regard to jurisdictional claims in published maps and institutional affiliations.

\section{Author details}

${ }^{1}$ College of Medicine and Health Sciences, Adigrat University, Tigray, Ethiopia. ${ }^{2}$ Department of Epidemiology and Biostatistics, Institute of Public Health, University of Gondar, Gondar, Ethiopia. ${ }^{3}$ School of Public Health, College of Medicine and Health Sciences, Bahir Dar University, P.O.Box 79, Bahir Dar, Ethiopia. ${ }^{4}$ College of Health Sciences, Debre Markos University, Debre Markos, Ethiopia.

Received: 19 September 2017 Accepted: 7 October 2018 Published online: 29 October 2018

\section{References}

1. World Health Organization, Unicef. Trends in maternal mortality: 1990 to 2013: estimates by WHO, UNICEF, UNFPA, The World Bank and the United Nations Population Division: executive summary. World Health Organization; 2014. Accessed at http://www.who.int/iris/handle/10665/112697.

2. Legesse $T$, Abdulahi M, Dirar A. Trends and causes of maternal mortality in Jimma University specialized hospital, Southwest Ethiopia: a matched casecontrol study. Int J Women's Health. 2017;9:307-13.

3. Thaddeus S, Maine D. Too far to walk: maternal mortality in context. Soc Sci Med. 1994;38(8):1091-110.

4. Acharya AS, Kaur R, Prasuna JG, Rasheed N. Making pregnancy safer-birth preparedness and complication readiness study among antenatal women attendees of a primary health center, Delhi. Indian journal of community medicine: official publication of Indian Association of Preventive \& social. Medicine. 2015;40(2):127.

5. Khanna J, Bergsjo P, Lashley K, Peters C, Sherrat D, Villar J. WHO antenatal care randomized trial: manual for the implementation of the new model. 2002.

6. Bankole A, Sedgh G, Okonofua F, Imarhiagbe C, Hussain R, Wulf D, et al. Birth preparedness and complication readiness: a matrix of shared responsibility. Revised. Journal of Clinical Medicine and Research. 2010; 2(4):55-60.

7. Gaym A. Maternal mortality studies in Ethiopia-magnitude, causes and trends. Ethiop Med J. 2009:47(2):95-108.

8. Tessema GA, Laurence CO, Melaku YA, Misganaw A, Woldie SA, Hiruye A, et al. Trends and causes of maternal mortality in Ethiopia during 1990-2013: findings from the global burden of diseases study 2013. BMC Public Health. 2017:17(1):160.

9. Ethiopia CSA, ORC Macro. Demographic and Health Survey 2016. Addis Ababa: Central Statistical Agency, Addis Ababa, Ethiopia; 2016.

10. Macro OR. Central Statistical Agency: Ethiopia demographic and health survey 2000. Calverton: ORC Macro; 2001.

11. Hogan MC, Foreman KJ, Naghavi M, Ahn SY, Wang M, Makela SM, et al. Maternal mortality for 181 countries, 1980-2008: a systematic analysis of progress towards millennium development goal 5. Lancet. 2010;375(9726): 1609-23.

12. Macro OR. Central Statistical Agency: Ethiopia demographic and health survey 2005. Calverton: ORC Macro; 2006.

13. World Health Organization. Birth and emergency preparedness in antenatal care. Standards for Maternal and Neonatal Care. Geneva: World Health Organization; 2006. p. 1-6.

14. Villar J, Ba'ageel H, Piaggio G, Lumbiganon P, Miguel Belizan J, Farnot U, Al-Mazrou Y, Carroli G, Pinol A, Donner A, Langer A, Nigenda G, Mugford M, Fox-Rushby J, Hutton G, Bergsjo P, Bakketeig L, Berendes H, Garcia J, Group WHOACTR. WHO antenatal care randomised trial for the evaluation of a new model of routine antenatal care. Lancet. 2001:357(9268):1551-64. https://doi.org/10.1016/S0140-6736(00)04722-X. 
15. Del Barco RC. Monitoring birth preparedness and complication readiness. Tools and indicators for maternal and newborn health 2004. Baltimore: JHPIEGO; 2004. p. 330. (USAID Award No. HRN-00-98-00043-00)

16. Botha AK, Maluwa A, Pindani M, Bultemeier K. Birth preparedness and complication readiness among postnatal mothers in Malawi. Health. 2013;5: 1486-93.

17. Mekbib T, Kassaye E, Getachew A, Tadesse T, Debebe A. The FIGO save the mothers initiative: the Ethiopia-Sweden collaboration. Int J Gynecol Obstet. 2003;81(1):93-102.

18. Kwast BE, Rochat RW, Kidane-Mariam W. Maternal mortality in Addis Ababa, Ethiopia. Stud Fam Plan. 1986;17(6):288-301.

19. Abdella A. Maternal mortality trend in Ethiopia. Ethiop J Health Dev. 2010; 24(1).

20. Worku AG, Yalew AW, Afework MF. Maternal complications and women's behavior in seeking care from skilled providers in North Gondar, Ethiopia. PLoS One. 2013;8(3):e60171.

21. Ethiopia federal ministry of health. Basic Emergency Obstetric \& Newborn Care (BEmONC) Training Manual. 2014.

22. Egger M, Smith GD, Schneider M, Minder C. Bias in meta-analysis detected by a simple, graphical test. BMJ. 1997;315(7109):629-34.

23. Huedo-Medina TB, Sánchez-Meca J, Marín-Martínez F, Botella J. Assessing heterogeneity in meta-analysis: Q statistic or $\mathrm{I}^{2}$ index? Psychol Methods. 2006;11(2):193.

24. Borenstein $M$, Hedges $L$, Rothstein $H$. Meta-analysis fixed effect vs. random effects. 2007. Available at: http://www.Meta-analysis.com. Accessed 4 Oct 2009. 2008.

25. Duval S, Tweedie R. A nonparametric "trim and fill" method of accounting for publication bias in meta-analysis. JASA. 2000;95(449):89-98.

26. Dimtsu B, Bugssa G. Assessment of knowledge and practice towards birth preparedness and complication readiness among women in Mekelle, Northern Ethiopia: descrptive crossectional. Int J Pharm Sci Res. 2014;5(10): 4293.

27. Bitew $Y$, Awoke W, Chekol S. Birth preparedness and complication readiness practice and associated factors among pregnant women, Northwest Ethiopia. Int Sch Res Notices. 2016;2016:8. Accessed at https://doi.org/10. 1155/2016/8727365

28. Gebre M, Gebremariam A, Abebe TA. Birth preparedness and complication readiness among pregnant women in Duguna Fango District, Wolayta zone, Ethiopia. PLoS One. 2015;10(9):e0137570.

29. Hailu M, Gebremariam A, Alemseged F, Deribe K. Birth preparedness and complication readiness among pregnant women in southern Ethiopia. PLoS One. 2011;6(6):e21432.

30. Begashaw B, Tesfaye $Y$, Zelalem E, Ubong U, Kumalo A. Assessment of birth preparedness and complication readiness among pregnant mothers attending ante Natal Care Service in Mizan-Tepi University Teaching Hospital, South West Ethiopia. Clinics Mother Child Health. 2017;14(257):2.

31. Zepre K, Kaba M. Birth preparedness and complication readiness among rural women of reproductive age in abeshige district, guraghe zone, snnPr, ethiopia. Int J Womens Health. 2017:9:11.

32. Hiluf M, Fantahun M. Birth preparedness and complication readiness among women in Adigrat town, North Ethiopia. Ethiop J Health Dev. 2008;22(1):14-20.

33. Bishaw W, Awoke W, Teshome M. Birth Preparedness and Complication Readiness and Associated Factors among Pregnant Women in Basoliben District, Amhara Regional State, Northwest Ethiopia, 2013. Primary Health Care. 2014;4:171. https://doi.org/10.4172/2167-1079.1000171.

34. Kaso M, Addisse M. Birth preparedness and complication readiness in robe Woreda, Arsi zone, Oromia region, Central Ethiopia: a cross-sectional study. Reprod Health. 2014;11(1):55.

35. Markos D, Bogale D. Birth preparedness and complication readiness among women of child bearing age group in Goba woreda, Oromia region Ethiopia. BMC Pregnancy Childbirth. 2014;14(1):282

36. Musa A, Amano A. Determinants of birth preparedness and complication readiness among pregnant woman attending antenatal Care at Dilchora Referral Hospital,Dire Dawa City, East Ethiopia. Gynecol Obstet (Sunnyvale). 2016;6(2):356.

37. Isaac BD, Dego BD, Baruch ZR. Birth preparation practices and recognition of danger signs among pregnant women in Ethiopia African. J Nurs Midwifery. 2016:4(2):603-12.

38. Tiku S. Awareness on birth preparedness and complication readiness among antenatal care clients in Federal Police Referral Hospital Addis Ababa, Ethiopia. Am J Health Res. 2015;3(6):362-7.
39. Kabakyenga JK, Östergren P-O, Turyakira E, Pettersson KO. Knowledge of obstetric danger signs and birth preparedness practices among women in rural Uganda. Reprod Health. 2011;8(1):33.

40. Jatta FO, Lu Y-Y, Chang C-L, Liu C-Y. Pregnant women's awareness of antenatal danger signs and birth preparedness in rural Gambia. Afr J Midwifery Womens Health. 2014;8(4):189-94.

41. Mandal T, Biswas R, Bhattacharya S, Das D. Birth preparedness and complication readiness among recently delivered women in a rural area of Darjeeling, West Bengal, India. Am Med Student Res J. 2015;2(1):14-20.

42. Onayade A, Akanbi O, Okunola H, Oyeniyi C, Togun O, Sule S. Birth preparedness and emergency readiness plans of antenatal clinic attendees in Ile-ife, Nigeria. Niger Postgrad Med J. 2010;17(1):30-9.

43. Mutiso S, Qureshi Z, Kinuthia J. Birth preparedness among antenatal clients. East Afr Med J. 2008;85(6):275-83.

44. Urassa DP, Pembe AB, Mganga F. Birth preparedness and complication readiness among women in Mpwapwa district, Tanzania. Tanzania J Health Res. 2012;14(1).

45. Kuganab-Lem RB, Dogudugu R, Kanton L. Birth preparedness and complication readiness: a study of postpartum women in a rural district of Ghana. Public Health Res. 2014:4(6):225-33.

46. Emma-Ukaegbu U, Nwokeukwu H, Uzochukwu B. An assessment of birth preparedness and complication readiness in antenatal women in Umuahia north local government area, Abia State, Nigeria. Age. 2013;20:20-4

47. Ibadin $\mathrm{SH}$, Adam VY, Adeleye O, Okojie OH. Birth preparedness and complication readiness among pregnant women in a rural community in southern Nigeria. S Afr J Obstet Gynaecol. 2016;22(2):47-51.

48. Moran AC, Sangli G, Dineen R, Rawlins B, Yaméogo M, Baya B. Birthpreparedness for maternal health: findings from Koupéla district, Burkina Faso. J Health Popul Nutr. 2006;24(4):489.

49. Karkee R, Lee AH, Binns CW. Birth preparedness and skilled attendance at birth in Nepal: implications for achieving millennium development goal 5. Midwifery. 2013;29(10):1206-10.

50. Omari PK, Afrane YA, Ouma P. Birth Preparedness and Complication Readiness among Women Attending Antenatal Care Clinic in Health Facilities within Bureti Sub County of Kericho County, Kenya. Am J Med Med Sci. 2016;6(4):123-8.

51. Kaur A, Kaur M, Kaur R. Birth preparedness among antenatal mothers. Nurs Midwifery Res. 2015;11(4):153.

52. Ethiopia: too many deaths in childbirth as women opt out of healthcare. Accessed at https://www.worldhunger.org/ethiopia-too-many-deaths-inchildbirth/. The Guardian. may 05/2012. Accessed 13 Oct 2017.

53. Agbodohu D. Birth Preparedness and Complication Readiness Among Expectant Mothers at the Ridge Regional Hospital. Accra: University of Ghana; 2013.

54. Mousa HA, Alfirevic Z. Treatment for primary postpartum haemorrhage. Cochrane database of systematic reviews. 2007:(1).

55. McLintock C, James A. Obstetric hemorrhage. J Thromb Haemost. 2011;9(8): 1441-51.

56. Soubeiga D, Gauvin L, Hatem MA, Johri M. Birth Preparedness and Complication Readiness (BPCR) interventions to reduce maternal and neonatal mortality in developing countries: systematic review and metaanalysis. BMC Pregnancy Childbirth. 2014;14(1):129.

57. Abou-Zahr CL, Wardlaw TM, Organization WH. Antenatal care in developing countries: promises, achievements and missed opportunities: an analysis of trends, levels and differentials, 1990-2001. 2003.

58. Nimavat KA, Mangal AD, Unadkat SV, Yadav SB. A study of birth preparedness of women in Jamnagar district, Gujarat, India. International Journal Of Community Medicine And Public Health. 2016;3(9):2403-8. 